ARTICLE

https://doi.org/10.1038/s41467-020-14380-3

\title{
Reversible interconversion between methanol- diamine and diamide for hydrogen storage based on manganese catalyzed (de)hydrogenation
}

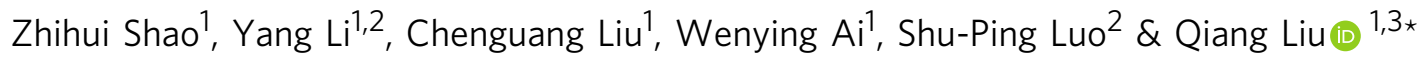

The development of cost-effective, sustainable, and efficient catalysts for liquid organic hydrogen carrier systems is a significant goal. However, all the reported liquid organic hydrogen carrier systems relied on the use of precious metal catalysts. Herein, a liquid organic hydrogen carrier system based on non-noble metal catalysis was established. The Mn-catalyzed dehydrogenative coupling of methanol and $N, N^{\prime}$-dimethylethylenediamine to form $\mathrm{N}, \mathrm{N}^{\prime}$-(ethane-1,2-diyl)bis ( $\mathrm{N}$-methylformamide), and the reverse hydrogenation reaction constitute a hydrogen storage system with a theoretical hydrogen capacity of $5.3 \mathrm{wt} \%$. A rechargeable hydrogen storage could be achieved by a subsequent hydrogenation of the resulting dehydrogenation mixture to regenerate the $\mathrm{H}_{2}$-rich compound. The maximum selectivity for the dehydrogenative amide formation was $97 \%$.

\footnotetext{
${ }^{1}$ Center of Basic Molecular Science (CBMS), Department of Chemistry, Tsinghua University, Beijing 100084, China. ${ }^{2}$ State Key Laboratory Breeding Base of Green Chemistry-Synthesis Technology, Zhejiang University of Technology, Hangzhou 310014, China. ${ }^{3}$ School of Biotechnology and Health Sciences, Wuyi University, Jiangmen, Guangdong 529090, China. *email: qiang_liu@mail.tsinghua.edu.cn
} 
ydrogen has long been regarded as one of the most promising sustainable energy carriers because it has a high mass energy density, can be efficiently transformed into electricity by fuel cells, and generates only water during combustion $^{1-4}$. In recent years, significant progress has been made in the generation of hydrogen from renewable energy sources and the development of efficient hydrogen-powered fuel cells ${ }^{5-8}$. However, hydrogen has not been widely used as an energy source because its storage is challenging. There are economic and safety concerns associated with the compressed and cryogenic liquid hydrogen ${ }^{9,10}$, therefore reversible hydrogen storage in chemical bonds via catalytic hydrogenation/dehydrogenation reactions is a promising technique ${ }^{11,12}$. Formic acid ${ }^{13-16}$, formaldehyde ${ }^{17,18}$, and methanol ${ }^{19-23}$ have been extensively studied as molecular hydrogen carriers. However, $\mathrm{H}_{2}$ release from these compounds involves generation of $\mathrm{CO}_{2}$, and $\mathrm{H}_{2}$ cannot be readily reloaded because the liquid carriers are consumed. The need to use stoichiometric amounts of bases and the low hydrogen capacity of formic acid (4.3 wt\%) further limit such approaches. To develop more efficient hydrogen storage systems, liquid organic hydrogen carriers (LOHCs) have emerged as a powerful strategy, in which a pair of $\mathrm{H}_{2}$-rich and $\mathrm{H}_{2}$-lean liquid organic compounds can repeatedly release and unload $\mathrm{H}_{2}{ }^{24-28}$. Early LOHCs studies focused on the dehydrogenation of cycloalkanes and the reverse hydrogenation of aromatics, but harsh reaction conditions (usually $>250^{\circ} \mathrm{C}$ ) were required ${ }^{29,30}$. To lower the endothermicity, LOHCs systems based on nitrogen-containing organic hydrides $^{24}$, e.g., $N$-heterocycles, were developed. These have high $\mathrm{H}_{2}$ capacities, in the range $5.3-7.3 \mathrm{wt} \%{ }^{31-37}$. These systems can be promoted by various homogeneous and heterogeneous catalysts $^{38-40}$ under relatively mild conditions (Fig. 1a). Besides, the Milstein and Prakash groups reported LOHCs systems via $\mathrm{Ru}$-catalyzed amide bond formation and hydrogenation (Fig. 1b) ${ }^{41-45}$. Notably, widely available and inexpensive amines and alcohols can be used as hydrogen carriers in these systems. Despite the favorable thermodynamics, usually $<80 \%$ selectivity for dehydrogenative amide bond formation was reached ${ }^{43-45}$.

In addition to identifying renewable and inexpensive liquid molecular hydrogen carriers, the development of cost-effective, sustainable, and efficient catalysts for LOHCs systems is a significant goal. To the best of our knowledge, all the reported LOHCs systems relied on the use of precious metal catalysts. The development of efficient catalytic systems based on earthabundant non-noble metals is therefore important. On the basis of recent achievements in Mn-catalyzed hydrogenation and dehydrogenation reactions ${ }^{46-60}$, we have developed the LOHCs system based on Mn-catalyzed dehydrogenative amide bond formation and the reverse hydrogenation reaction. Remarkably, the maximum selectivity for the dehydrogenative condensation of methanol and $N, N^{\prime}$-dimethylethylenediamine (DMEDA) to form $N, N^{\prime}$-(ethane-1,2-diyl)bis( $N$-methylformamide) was $97 \%$ (Fig. 1c).

\section{Results and discussion}

Optimization of the reaction conditions. We commenced the investigation by exploring the catalytic activities of a series of NNP- and PNP-pincer Mn complexes I to VII in the dehydrogenative condensation of DMEDA (1) and methanol (Table 1). In the presence of PhPNP-complex VI (2 mol\%), and $t \mathrm{BuOK}(4 \mathrm{~mol} \%)$ in 1,4-dioxane, full conversion of 1 was achieved along with formation of the desired product $N, N^{3}$ (ethane-1,2-diyl)bis( $N$-methylformamide) (2a) in $86 \%$ yield (Table 1, entry 6). $N$-methyl- $N$-[2-(methylamino)ethyl]formamide (2b) and 3-methyl-1-methyleneimidazolidin-1-ium (3) were generated in $9 \%$ and $5 \%$ yield, respectively. Under the same a

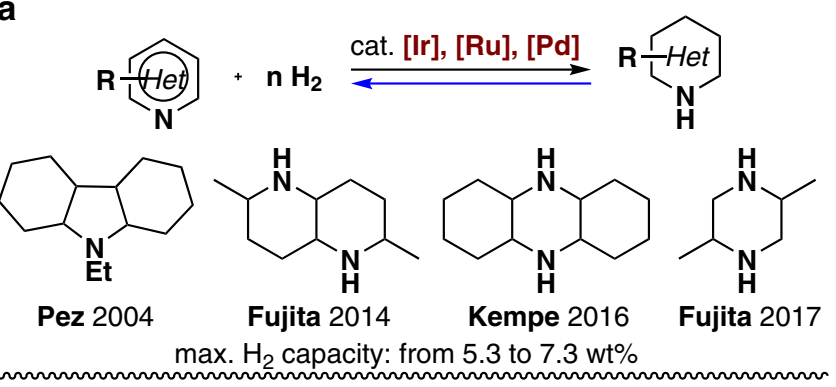

b<smiles>O=C1CNC(=O)CN1</smiles>

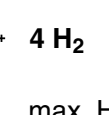

$\underset{\text { max. 93\% selec. }}{\stackrel{\text { cat. [Ru] }}{\rightleftarrows}}$

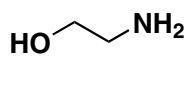

$\overbrace{\substack{\mathrm{CHO}^{\prime} \\ \mathrm{N}}}^{\mathrm{CHO}}$

$4 \mathrm{H}_{2}$

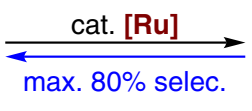

Milstein 2015

max. $\mathrm{H}_{2}$ capacity: $5.3 \mathrm{wt} \%$<smiles>CNCCNC</smiles>

Prakash 2017<smiles>O=C1CCC(=O)N1CCN1C(=O)CCC1=O</smiles>

$\mathbf{8} \mathrm{H}_{2} \underset{\text { max. } 70 \% \text { selec. }}{\stackrel{\text { cat. [Ru] }}{\rightleftarrows}}$
max. $\mathrm{H}_{2}$ capacity: 6.7 wt $\%$<smiles>C[13CH][13C](O)[14CH2]O</smiles><smiles>O=C1NCCN1</smiles>

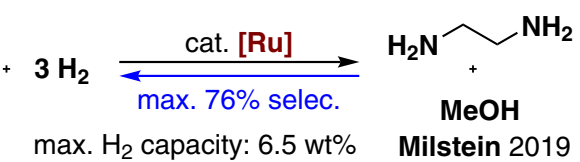

c

C

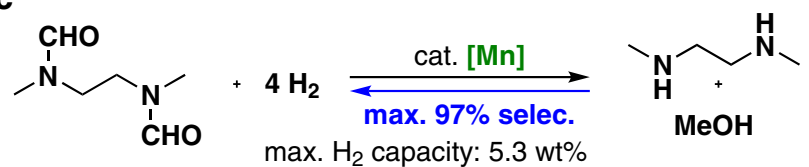

Fig. 1 Hydrogen storage systems based on $\mathbf{N}$-containing organic hydrides. a Heterocycles hydrogenation and dehydrogenation reactions. b Amide bond formation and Hydrogenation reactions. c Mn-catalyzed hydrogenation and dehydrogenation reactions.

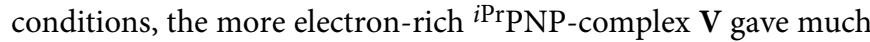
lower selectivity for 2a (Table 1, entry 5), and the NNPcomplexes I-IV showed no activity (Table 1, entries 1-4).

Various reaction parameters were screened to further improve the efficiency of this transformation (Table 2). Use of $<6$ equiv of $\mathrm{MeOH}$ decreased the selectivity for $\mathbf{2 a}$ and increased production of monoamide $\mathbf{2 b}$ (Table 2 , entry 3 ). The added base also crucially affected the selectivity. The best choice was $t \mathrm{BuOK} ; \mathrm{BuONa}$ gave much worse results (Table 2, entries 1 and 4). When a weaker base, i.e., $\mathrm{KOH}$, was used, the reaction yield of $\mathbf{2 a}$ decreased to $71 \%$ (Table 2, entry 6). Concentration screening showed that $0.42-0.63 \mathrm{M} 1$ gave the highest selectivity for the desired product 2a (Table 2, entries 1 and 8). Decreasing the reaction temperature from 165 to $150{ }^{\circ} \mathrm{C}$ diminished the reaction efficiency (Table 2, entry 10). We assumed that $\mathrm{H}_{2}$ generated during the reaction would accumulate in the closed system, and this would inhibit dehydrogenation. To verify this assumption, the evolved gas was released from the reaction system after reaction for $2 \mathrm{~h}$, and the reaction was then performed for a further $6 \mathrm{~h}$ at $165^{\circ} \mathrm{C}$. The yield of $2 \mathbf{a}$ increased to $97 \%$ (Table 2, entry 11). The evolved gas $(24 \mathrm{~mL})$ was collected in a gas buret. GC analysis showed that the 
Table 1 Mn-catalyzed dehydrogenative condensation of 1 and $\mathrm{CH}_{3} \mathrm{OH}$.

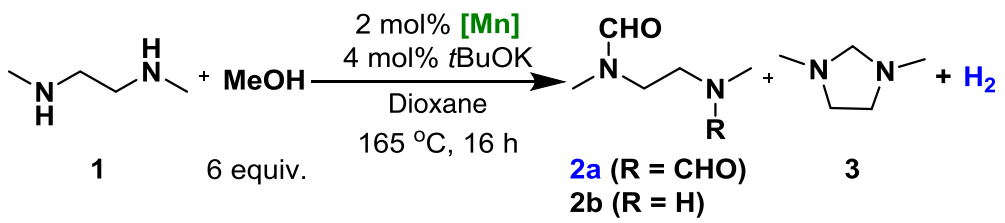

\begin{tabular}{lllllll}
\hline Entry & [Mn] & Conv. [\%] & $\mathbf{2 a}[\%]$ & $\mathbf{2 b}[\%]$ & $\mathbf{3 ~ [ \% ]}$ & $\mathbf{H}_{2}[\%]^{\mathbf{a}}$ \\
\hline 1 & I & 0 & 0 & 0 & 0 & Trace \\
2 & II & 0 & 0 & 0 & 0 & Trace \\
3 & III & 0 & 0 & 0 & 0 & Trace \\
4 & IV & 0 & 0 & 0 & 0 & Trace \\
5 & V & $>99$ & 31 & 24 & 45 & $48(>99.9 \%)$ \\
6 & VI & $>99$ & $\mathbf{8 6}$ & $\mathbf{9}$ & $\mathbf{5}$ & $\mathbf{9 2 ( 9 5 . 5 \% )}$ \\
\hline
\end{tabular}

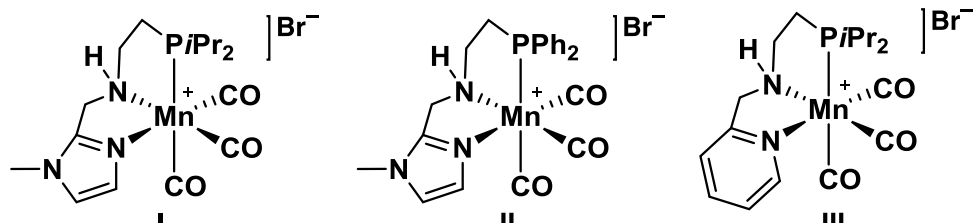

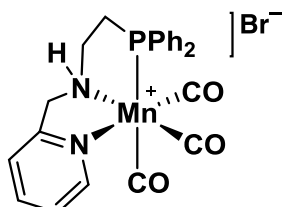

IV

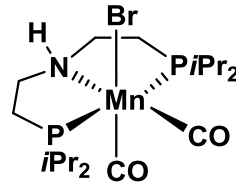

V

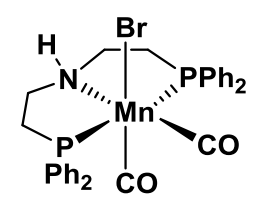

VI

Reaction conditions: $1(0.25 \mathrm{mmol}), \mathrm{MeOH}(1.5 \mathrm{mmol}), \mathbf{M n}(2 \mathrm{~mol} \%), \mathrm{BuOK}(4 \mathrm{~mol} \%)$ and 1,4-dioxane $(0.4 \mathrm{ml})$ were reacted at $165^{\circ} \mathrm{C}$ for $16 \mathrm{~h}$. The conversion and yield were determined by NMR and GC using 1,1,2,2-tetrachloroethane as the internal standard.

aThe yield of $\mathrm{H}_{2}$ was calculated on the basis of maximum $\mathrm{H}_{2}$ evolution with respect to $100 \%$ conversion of $\mathbf{1 - 2 a}\left(4 \mathrm{mmol} \mathrm{H}_{2}\right.$ per $\mathrm{mmol}$ of $\left.\mathbf{1}\right)$. The $\mathrm{H}_{2}$ purity is shown in parentheses.

Table 2 Optimization of dehydrogenative condensation of $1 \mathrm{a}$ and $\mathrm{CH}_{3} \mathrm{OH}$.

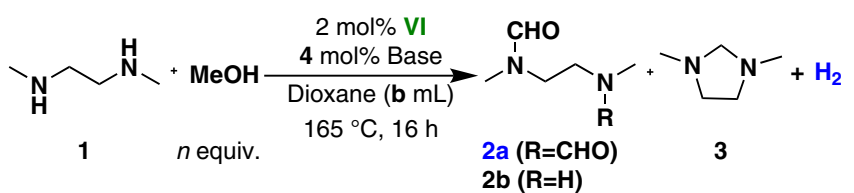

\begin{tabular}{|c|c|c|c|c|c|c|c|}
\hline Entry & $n$ & Base & $b[\mathrm{~mL}]$ & $2 a$ [\%] & 2b [\%] & 3 [\%] & $\mathbf{H}_{2}[\%]^{d}$ \\
\hline 1 & 6 & tBuOK & 0.4 & 86 & 9 & 5 & $92(95.5 \%)$ \\
\hline 2 & 8 & tBuOK & 0.4 & 86 & 5 & 8 & $89(94.8 \%)$ \\
\hline 3 & 4 & tBuOK & 0.4 & 80 & 13 & 7 & $85(96.7 \%)$ \\
\hline 4 & 6 & tBuONa & 0.4 & 30 & 22 & 46 & $48(>99.9 \%)$ \\
\hline 5 & 6 & KOMe & 0.4 & 85 & 10 & 5 & $90(98.5 \%)$ \\
\hline 6 & 6 & $\mathrm{KOH}$ & 0.4 & 71 & 14 & 15 & $80(99.8 \%)$ \\
\hline 7 & 6 & tBuOK & 0.2 & 77 & 8 & 15 & $82(96.4 \%)$ \\
\hline 8 & 6 & tBuOK & 0.6 & 86 & 11 & 3 & $90(93.5 \%)$ \\
\hline 9 & 6 & tBuOK & 1 & 77 & 17 & 5 & $88(90.2 \%)$ \\
\hline $10^{a}$ & 6 & tBuOK & 0.4 & 76 & 14 & 7 & $84(97.8 \%)$ \\
\hline $11^{b}$ & 6 & tBuOK & 0.4 & 97 & $<1$ & 2 & $98(98.7 \%)$ \\
\hline $12^{c}$ & 6 & tBuOK & 0.4 & 93 & 5 & 2 & 90 (>99.9\%) \\
\hline
\end{tabular}


$\mathrm{H}_{2}$ purity in the gas mixture was $98.7 \%$ and the yield was $98 \%$. In addition to $\mathrm{H}_{2}, 1.3 \% \mathrm{CO}$ was detected as a result of decarbonylation of the formaldehyde intermediate. The generation of $\mathrm{CO}$ was completely suppressed by adding $2 \mathrm{~mol} \%$ of catalyst VI in two equal portions, before and after gas release, after reaction for $2 \mathrm{~h}$. This procedure provided released $\mathrm{H}_{2}$ of purity over $99.9 \%$ (Table 2, entry 12).

We then turned our attention to the reverse reaction, hydrogenation of $\mathbf{2 a}$ to diamine $\mathbf{1}$ (Table 3). The NNP-pincer Mn catalyst IV was found to be the most active catalyst for this transformation (Supplementary Table 5). A decrease in the $\mathrm{H}_{2}$

\section{Table 3 Optimization of Hydrogenation of $2 a$.}

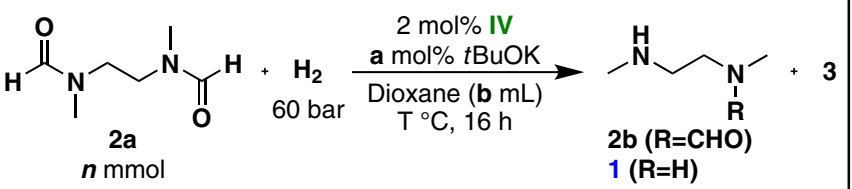

\begin{tabular}{llllllll} 
Entry & $\boldsymbol{n}$ [mmol] & $\boldsymbol{a}$ [mol\%] & $\boldsymbol{b}$ [mL] & $\boldsymbol{T}\left[{ }^{\circ} \mathbf{C}\right]$ & $\mathbf{2 b}[\%]$ & $\mathbf{1}[\%]$ & $\mathbf{3}[\%]$ \\
\hline 1 & 0.25 & 20 & 1 & 150 & 0 & 99 & 0 \\
$2^{a}$ & 0.25 & 20 & 1 & 150 & 37 & 61 & 0 \\
3 & 0.25 & 20 & 1 & 130 & 0 & 99 & 0 \\
4 & 0.25 & 20 & 1 & 110 & 0 & 99 & 0 \\
5 & 0.25 & 20 & 1 & 90 & 50 & 38 & 8 \\
6 & 0.25 & 10 & 1 & 110 & 15 & 76 & 0 \\
7 & 0.5 & 10 & 2 & 110 & 0 & 99 & 0 \\
8 & $\mathbf{0 . 5}$ & $\mathbf{2 . 5}$ & $\mathbf{2}$ & $\mathbf{1 1 0}$ & $\mathbf{0}$ & $\mathbf{9 9}$ & $\mathbf{0}$ \\
9 & $\mathbf{0 . 5}$ & $\mathbf{2 . 5}$ & $\mathbf{1}$ & $\mathbf{1 1 0}$ & $\mathbf{0}$ & $\mathbf{9 9}$ & $\mathbf{0}$ \\
10 & $\mathbf{0 . 5}$ & $\mathbf{2 . 5}$ & $\mathbf{0 . 4}$ & $\mathbf{1 1 0}$ & $\mathbf{0}$ & $\mathbf{9 9}$ & $\mathbf{0}$ \\
$11^{\mathrm{b}}$ & $\mathbf{0 . 5}$ & $\mathbf{5}$ & $\mathbf{1}$ & $\mathbf{1 8 0}$ & $\mathbf{5}$ & $\mathbf{9 4}$ & $\mathbf{0}$
\end{tabular}

Reaction conditions: $\mathbf{2 a}$, IV (2 mol\%), tBuOK, and 1,4-dioxane were reacted under 60 bar of $\mathrm{H}_{2}$ at a given temperature for $16 \mathrm{~h}$. The conversion and yield were determined by GC and NMR, respectively.

a 40 bar.

${ }^{b} \mathbf{V I}(3 \mathrm{~mol} \%), 80$ bar

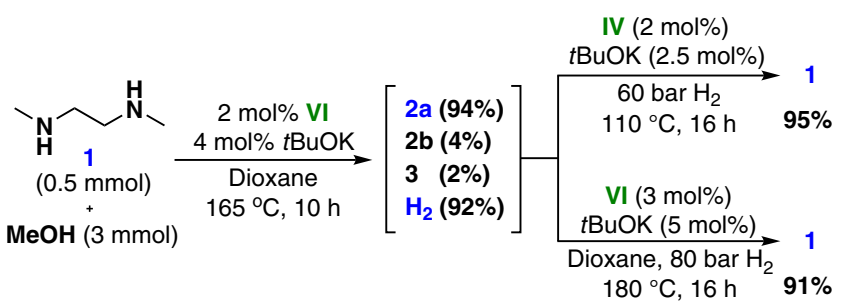

Fig. 2 Reversible interconversion between $\mathbf{1}$ /methanol and $\mathbf{2 a}$ by $\mathbf{M n -}$ catalyzed hydrogenation and dehydrogenation. pressure from 60 to 40 bar lowered conversion of the monoamide $\mathbf{2 b}$ to the fully hydrogenated product $\mathbf{1}$ at $150{ }^{\circ} \mathrm{C}$ (Table 3 , entry 2). Notably, this hydrogenation reaction proceeded smoothly at $110^{\circ} \mathrm{C}$, with an excellent yield of $\mathbf{1}$, when $2 \mathrm{~mol} \%$ of catalyst IV and $2.5 \mathrm{~mol} \%$ of $t \mathrm{BuOK}$ were used (Table 3, entry $8-10)$. For $0.25 \mathrm{mmol}$-scale reactions, a larger amount of base was needed to achieve the same level of selectivity (Table 3 , entries 1 and 6). The use of a single catalyst for both the dehydrogenation and hydrogenation reactions is desirable toward practical applications. We therefore optimized the hydrogenation of $\mathbf{2 a}$ with catalyst VI, the same catalyst as was used in the dehydrogenation reaction (Supplementary Table 8). Under harsh reaction conditions $\left(180^{\circ} \mathrm{C}, 80\right.$ bar of $\left.\mathrm{H}_{2}\right)$, a $94 \%$ yield of 1 was obtained with complex VI as the catalyst (Table 3, entry 11).

After establishing the optimum reaction conditions for both the dehydrogenative coupling of methanol and $\mathbf{1}$, and the hydrogenation of diamide $\mathbf{2 a}$, we performed Mn-catalyzed reversible interconversion between $\mathbf{1}$ /methanol and 2a (Fig. 2). The cycle began with dehydrogenation using 2 mol\% VI as the catalyst; this resulted in full conversion of 1 . The crude reaction mixture, $2 \mathrm{~mol} \% \mathrm{IV}$, and $2.5 \mathrm{~mol} \% \mathrm{tBuOK}$ were transferred to an autoclave for the reverse hydrogenation. The catalytic activity of IV was not decreased by the presence of the dehydrogenation catalyst VI. After one cycle, diamine 1 was recovered in $95 \%$ yield. Moreover, the reversible hydrogenation and dehydrogenation cycle could also be realized using the same catalyst VI, albeit with harsh reaction conditions for the $\mathrm{H}_{2}$-loading process. Compared with the corresponding LOHC system based on $\mathrm{Ru}$ catalysis $^{43}$, the Mn-catalyzed dehydrogenation process in this system required a higher reaction temperature $\left(165^{\circ} \mathrm{C}\right.$ vs $\left.120^{\circ} \mathrm{C}\right)$ and catalyst loading ( $2 \mathrm{~mol} \%$ vs $1 \mathrm{~mol} \%$ ), which has yet to be improved in the future works.

Control experiments. Under the optimized reaction conditions for catalyst VI bearing the $\mathrm{N}-\mathrm{H}$ moiety, the corresponding $\mathrm{N}$ methyl-substituted complex VII showed no reactivity for the dehydrogenative condensation of $\mathbf{1}$ and methanol, and gave only $7 \%$ conversion for the hydrogenation of $\mathbf{2 a}$ to $\mathbf{2 b}$. (Fig. 3) These results demonstrate the crucial role of the $\mathrm{N}-\mathrm{H}$ group in metal-ligand-cooperation for the (de)hydrogenation process. Furthermore, mercury and ligand poisoning experiments indicated that both hydrogenation and dehydrogenation reaction processes proceed with involvement of homogeneous molecular catalysts (Supplementary Tables 11-13).

Further mechanistic insights into the dehydrogenative condensation reaction were obtained by performing a series of control experiments (Fig. 4). The Mn complex VI-catalyzed dehydrogenation of methanol in the absence of diamine $\mathbf{1}$ only produced methyl formate (4) in $4 \%$ yield. This shows that dehydrogenative ester formation is unfavorable, therefore aminolysis of $\mathbf{4}$ with $\mathbf{1}$ is not the

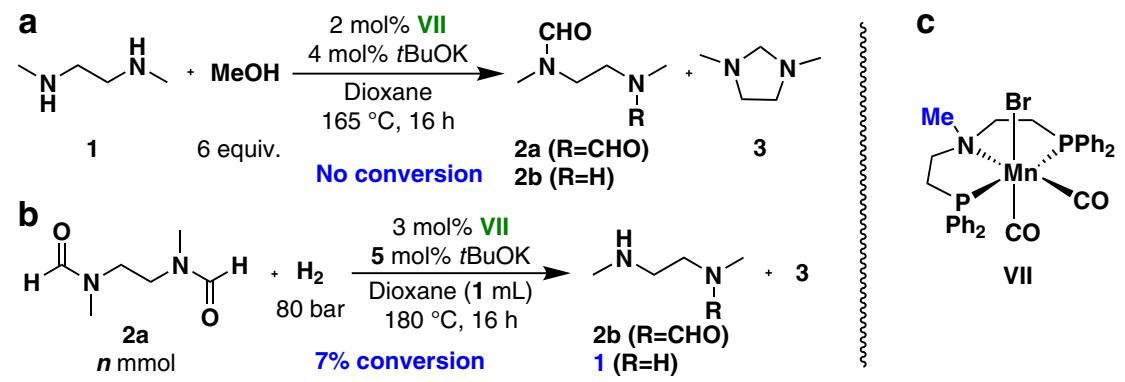

Fig. 3 Mn-catalyzed hydrogenation and dehydrogenation using N-methyl substituted catalyst VII. a VII-catalyzed Dehydrogenation reaction. b VIIcatalyzed hydrogenation reaction. c The structure of VII. 
major reaction pathway for Mn-catalyzed dehydrogenative amide formation (Fig. 4a). Significant amounts of $\mathrm{H}_{2}(14.6 \mathrm{~mL})$ and $\mathrm{CO}$ $(7.4 \mathrm{~mL})$ in a 2:1 ratio were generated in the dehydrogenation of methanol $(1.5 \mathrm{mmol})$. The use of paraformaldehyde instead of methanol led to the formation of $\mathbf{2 a}, \mathbf{2} \mathbf{b}$, and $\mathbf{3}$, albeit with lower selectivities (Fig. 4b). These results indicate that formaldehyde is a possible reaction intermediate in the dehydrogenative condensation of methanol with $\mathbf{1}$. Use of monoamide $\mathbf{2} \mathbf{b}$ as the starting material gave $\mathbf{2 a}$ in $92 \%$ yield. This shows that $\mathbf{2 b}$ is a likely intermediate in diamide formation (Fig. 4c). In the absence of a

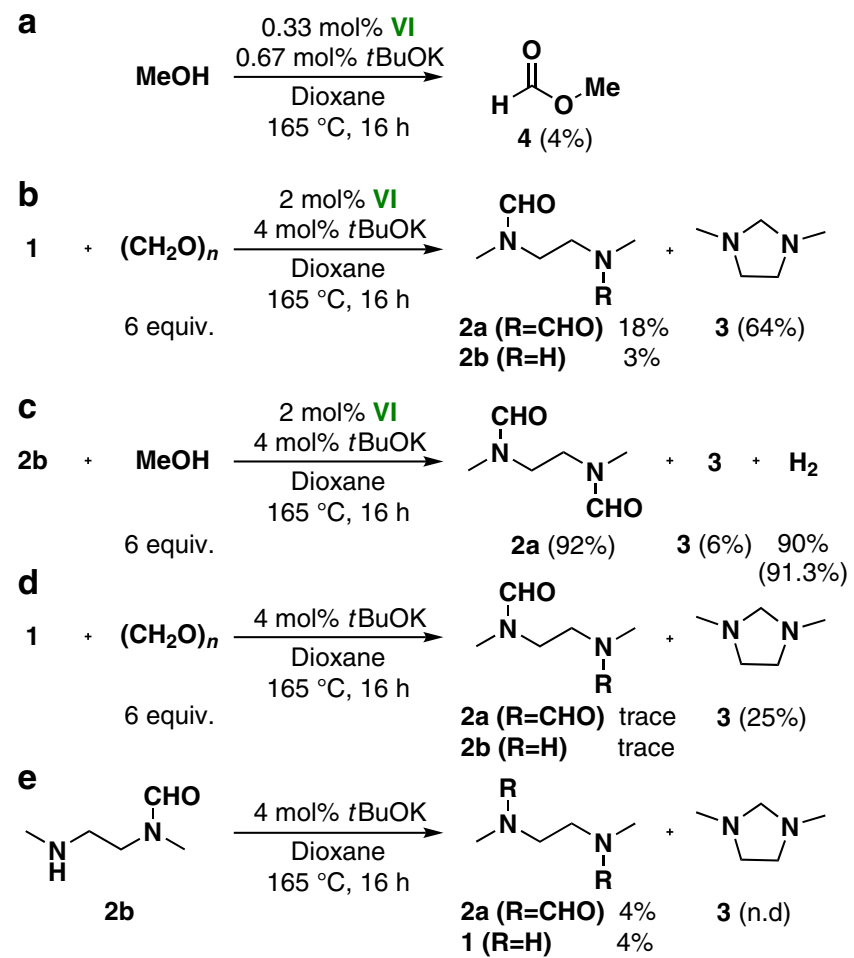

Fig. 4 Control experiments for mechanistic study. a VI-catalyzed dehydrogenation of methanol. $\mathbf{b}$ Dehydrogenative condensation of $\mathbf{1}$ with paraformaldehyde. $\mathbf{c}$ Dehydrogenative condensation of $\mathbf{2} \mathbf{b}$ with methanol. d Condensation of $\mathbf{1}$ and paraformaldehyde without $\mathrm{Mn}$ catalyst. e Reactivity of $\mathbf{2} \mathbf{b}$ without $\mathrm{Mn}$ catalyst.

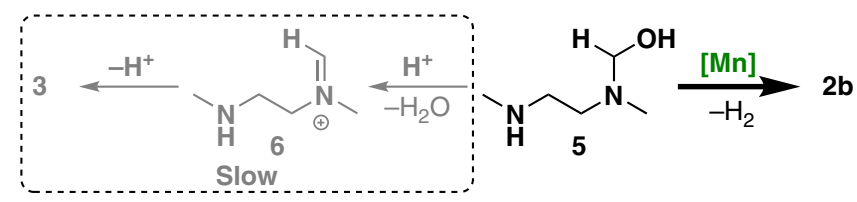

Fig. 5 Analysis of the competitive reaction pathways of intermediate $\mathbf{5}$.
Mn catalyst, 1 reacted with paraformaldehyde to form 3-methyl-1methyleneimidazolidin-1-ium (3) (Fig. 4d). In contrast, 3 was not produced from $\mathbf{2 b}$ under the same conditions (Fig. $4 \mathrm{e}$ ). This shows that $\mathbf{3}$ is formed by aminalization of $\mathbf{1}$ and formaldehyde formed in situ.

Accordingly, to prevent the formation of byproduct 3 in the catalytic dehydrogenative condensation reaction, the $\mathrm{Mn}$ catalyzed dehydrogenation of the hemiaminal intermediate $\mathbf{5}$ must be much faster than its dehydration under these reaction conditions (Fig. 5).

Proposed mechanism. Based on the above results and our previous studies of $\mathrm{Mn}$-catalyzed alcohol dehydrogenation ${ }^{61-64}$, plausible reaction pathways for the dehydrogenative condensation of methanol and $\mathbf{1}$ are proposed (Fig. 6). The dehydrogenation of methanol gives formaldehyde as a reaction intermediate. This reacts with one amine group of $\mathbf{1}$ to generate the hemiaminal species 5, which eliminates one molecule of $\mathrm{H}_{2}$ to give the monoamide intermediate $\mathbf{2 b}$. Reaction of $\mathbf{2} \mathbf{b}$ with another molecule of formaldehyde affords the final product $\mathbf{2 a}$ and one molecule of $\mathrm{H}_{2}$ is released. A possible minor reaction pathway is dehydrogenative ester formation from methanol to form methyl formate (4), which undergoes aminolysis with $\mathbf{1}$ to deliver diamide 2a. The decarbonylation of formaldehyde to $\mathrm{CO}$ and $\mathrm{H}_{2}$ can be prevented in this reaction system by fast condensation of formaldehyde with the amino groups of $\mathbf{1}$ and monoamide $\mathbf{2} \mathbf{b}$.

In summary, a LOHC system based on non-noble-metal catalysis was developed. The Mn-catalyzed dehydrogenative condensation of methanol and DMEDA to form $N, N^{\prime}$-(ethane1,2-diyl)bis( $N$-methylformamide), and the reverse hydrogenation reaction, gave unloading and loading of $\mathrm{H}_{2}$ in excellent yields with a theoretical hydrogen capacity of $5.3 \mathrm{wt} \%$. Reversible hydrogen storage was shown by subsequent hydrogenation of the resulting dehydrogenation mixture to regenerate $\mathrm{H}_{2}$-rich compounds. The maximum selectivity for the dehydrogenation reaction was $97 \%$.

\section{Methods}

General procedure for the dehydrogenation. All dehydrogenation experiments were carried out in a $25 \mathrm{~mL}$ pressure seal tube. In the argon atmosphere glovebox, [Mn], $t \mathrm{BuOK}$, solvent, $N, N^{\prime}$-dimethylethylenediamine $\mathbf{1}$, and $\mathrm{MeOH}$ were added sequentially to the seal tube equipped with a magnetic stir bar, The reaction mixture was stirred at given temperature for $16 \mathrm{~h}$ and cooled to room temperature. After the gas was released, the conversion of 1 was determined by NMR and the yield of products $\mathbf{2 a}, \mathbf{2} \mathbf{b}$, and $\mathbf{3}$ was determined by GC wiith 1,1,2,2-tetrachloroethane as the internal standard.

General procedure for the hydrogenation. All hydrogenation experiments were carried out in a Parr Instruments 4560 series autoclave $(300 \mathrm{~mL})$ containing an alloy plate with wells for seven $4 \mathrm{~mL}$ glass vials. In the argon atmosphere glovebox, $N, N$-(Ethane-1,2-diyl)bis( $N$-methylformamide) $\mathbf{2 a},[\mathbf{M n}], t \mathrm{BuOK}$, and solvent were added sequentially to the vial equipped with a magnetic stir bar, which was capped with a septum threaded with a syringe. The vial was placed in the alloy plate, which was then placed to the predried autoclave. Once sealed, the autoclave was purged three times with hydrogen, then pressurized to given pressure and

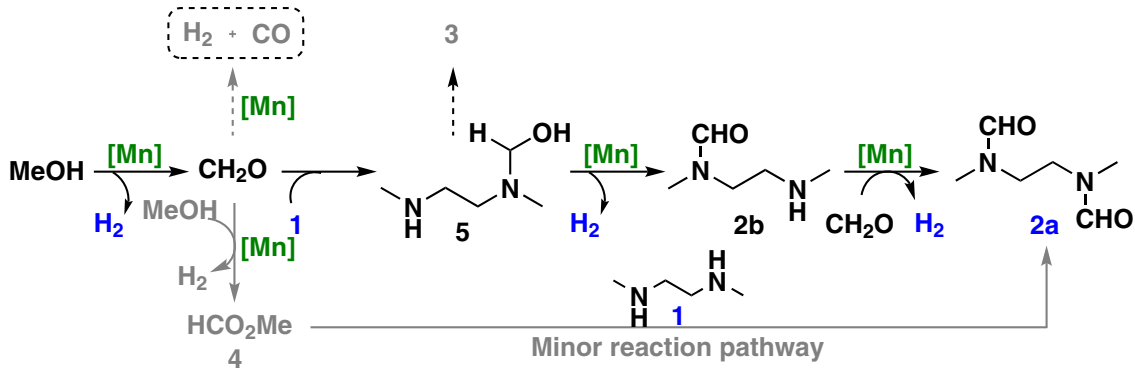

Fig. 6 Plausible reaction pathways for dehydrogenative condensation of methanol and $\mathbf{1 .}$ 
heated at given temperature for $16 \mathrm{~h}$. After reaction, the autoclave was cooled to $0{ }^{\circ} \mathrm{C}$, depressurized. The conversion and yield were determined by GC and NMR with 1,1,2,2-tetrachloroethane as the internal standard.

\section{Data availability}

The authors declare that all the data supporting the findings of this research are available within the article and its supplementary information.

Received: 4 September 2019; Accepted: 5 December 2019; Published online: 30 January 2020

\section{References}

1. Jones, L. W. Liquid hydrogen as a fuel for the future. Science 174, 367-370 (1971).

2. Bockris, J. O. \& M. A Hydrogen economy. Science 176, 1323-1323 (1972).

3. Crabtree, G. W., Dresselhaus, M. S. \& Buchanan, M. V. The hydrogen economy. Phys. Today 57, 39-44 (2004).

4. Satyapal, S., Petrovic, J., Read, C., Thomas, G. \& Ordaz, G. The U.S. Department of Energy's National Hydrogen Storage Project: progress towards meeting hydrogen-powered vehicle requirements. Catal. Today 120, 246-256 (2007).

5. Navarro, R. M., Sanchez-Sanchez, M. C., Alvarez-Galvan, M. C. \& Fierro, J. L. G. Encyclopedia of Inorganic and Bioinorganic Chemistry: $\mathrm{H}_{2}$ production from renewables (John Wiley \& Sons, 2011).

6. Eberle, U., Müller, B. \& von Helmolt, R. Fuel cell electric vehicles and hydrogen infrastructure: status 2012. Energy Environ. Sci. 5, 8780-8798 (2012).

7. El-Emam, R. S. \& Ozcan, H. Comprehensive review on the techno-economics of sustainable large-scale clean hydrogen production. J. Clean. Prod. 220, 593-609 (2019).

8. Staffell, I. et al. The role of hydrogen and fuel cells in the global energy system. Energy Environ. Sci. 12, 463-491 (2019).

9. Sadaghiani, M. S. \& Mehrpooya, M. Introducing and energy analysis of a novel cryogenic hydrogen liquefaction process configuration. Int. J. Hydrog. Energy 42, 6033-6050 (2017).

10. Sreedhar, I., Kamani, K. M., Kamani, B. M., Reddy, B. M. \& Venugopal, A. A Bird's Eye view on process and engineering aspects of hydrogen storage. Renew. Sust. Energy Rev. 91, 838-860 (2018).

11. Eberle, U., Felderhoff, M. \& Schüth, F. Chemical and physical solutions for hydrogen storage. Angew. Chem. Int. Ed. 48, 6608-6630 (2009).

12. Dalebrook, A. F., Gan, W., Grasemann, M., Moret, S. \& Laurenczy, G. Hydrogen storage: beyond conventional methods. Chem. Commun. 49, 8735-8751 (2013).

13. Fellay, C., Dyson, P. J. \& Laurenczy, G. A viable hydrogen-storage system based on selective formic acid decomposition with a ruthenium catalyst. Angew. Chem. Int. Ed. 47, 3966-3968 (2008).

14. Boddien, A. et al. Efficient dehydrogenation of formic acid using an iron catalyst. Science 333, 1733-1736 (2011)

15. Hull, J. F. et al. Reversible hydrogen storage using $\mathrm{CO}_{2}$ and a protonswitchable iridium catalyst in aqueous media under mild temperatures and pressures. Nat. Chem. 4, 383-388 (2012).

16. Mellmann, D., Sponholz, P., Junge, H. \& Beller, M. Formic acid as a hydrogen storage material-development of homogeneous catalysts for selective hydrogen release. Chem. Soc. Rev. 45, 3954-3988 (2016).

17. Heim, L. E., Schlörer, N. E., Choi, J.-H. \& Prechtl, M. H. G. Selective and mild hydrogen production using water and formaldehyde. Nat. Commun. 5, 3621 (2014).

18. Trincado, M. et al. Homogeneously catalysed conversion of aqueous formaldehyde to H2 and carbonate. Nat. Commun. 8, 14990 (2017).

19. Palo, D. R., Dagle, R. A. \& Holladay, J. D. Methanol Steam Reforming for Hydrogen Production. Chem. Rev. 107, 3992-4021 (2007).

20. Nielsen, M. et al. Low-temperature aqueous-phase methanol dehydrogenation to hydrogen and carbon dioxide. Nature 495, 85-89 (2013).

21. Rodríguez-Lugo, R. E. et al. A homogeneous transition metal complex for clean hydrogen production from methanol-water mixtures. Nat. Chem. 5, 342-347 (2013).

22. Lin, L. et al. Low-temperature hydrogen production from water and methanol using Pt/a-MoC catalysts. Nature 544, 80-83 (2017).

23. Kothandaraman, J., Kar, S., Goeppert, A., Sen, R. \& Prakash, G. K. S. Advances in homogeneous catalysis for low temperature methanol reforming in the context of the methanol economy. Top. Catal. 61, 542-559 (2018).

24. Crabtree, R. H. Hydrogen storage in liquid organic heterocycles. Energy Environ. Sci. 1, 134-138 (2008).

25. Teichmann, D., Arlt, W., Wasserscheid, P. \& Freymann, R. A future energy supply based on liquid organic hydrogen carriers (LOHC). Energy Environ. Sci. 4, 2767-2773 (2011)
26. Yadav, M. \& Xu, Q. Liquid-phase chemical hydrogen storage materials. Energy Environ. Sci. 5, 9698-9725 (2012).

27. Preuster, P., Papp, C. \& Wasserscheid, P. Liquid organic hydrogen carriers (LOHCs): toward a hydrogen-free hydrogen economy. Acc. Chem. Res. 50, 74-85 (2017)

28. Zou, Y.-Q., von Wolff, N., Anaby, A., Xie, Y. \& Milstein, D. Ethylene glycol as an efficient and reversible liquid-organic hydrogen carrier. Nat. Catal. 2, 415-422 (2019).

29. Taube, M., Rippin, D. W. T., Cresswell, D. L. \& Knecht, W. A system of hydrogen-powered vehicles with liquid organic hydrides. Int. J. Hydrog. Energy 8, 213-225 (1983).

30. Schildhauer, T., Newson, E. \& Müller, S. The equilibrium constant for the methylcyclohexane-toluene system. J. Catal. 198, 355-358 (2001)

31. Pez, G. P., Scott, A. R., Cooper, A. C. \& Cheng, H. Hydrogen storage by reversible hydrogenation of pi-conjugated substrates. EP 1475349 (2004).

32. Pez, G. P., et al. Hydrogen storage by reversible hydrogenation of piconjugated substrates. US 7351395B1 (2008).

33. Yamaguchi, R., Ikeda, C., Takahashi, Y. \& Fujita, K.-i Homogeneous catalytic system for reversible dehydrogenation-hydrogenation reactions of nitrogen heterocycles with reversible interconversion of catalytic species. J. Am. Chem. Soc. 131, 8410-8412 (2009).

34. Fujita, K.-i, Tanaka, Y., Kobayashi, M. \& Yamaguchi, R. Homogeneous perdehydrogenation and perhydrogenation of fused bicyclic n-heterocycles catalyzed by iridium complexes bearing a functional bipyridonate ligand. $J$ Am. Chem. Soc. 136, 4829-4832 (2014).

35. Chakraborty, S., Brennessel, W. W. \& Jones, W. D. A molecular iron catalys for the acceptorless dehydrogenation and hydrogenation of N-heterocycles. $J$. Am. Chem. Soc. 136, 8564-8567 (2014).

36. Forberg, D. et al. Single-catalyst high-weight\% hydrogen storage in an Nheterocycle synthesized from lignin hydrogenolysis products and ammonia. Nat. Commun. 7, 13201 (2016).

37. Fujita, K.-i, Wada, T. \& Shiraishi, T. Reversible interconversion between 2,5 dimethylpyrazine and 2,5-dimethylpiperazine by iridium-catalyzed hydrogenation/dehydrogenation for efficient hydrogen storage. Angew. Chem. Int. Ed. 56, 10886-10889 (2017)

38. Amende, M. et al. Model catalytic studies of liquid organic hydrogen carriers dehydrogenation and decomposition mechanisms of dodecahydro- $\mathrm{N}$ ethylcarbazole on Pt (111). ACS Catal. 4, 657-665 (2014).

39. Yang, M. et al. Study of hydrogenation and dehydrogenation of 1methylindole for reversible onboard hydrogen storage application. Int. J. Hydrog. Energy 43, 8868-8876 (2018).

40. Oh, J. et al. 2-(N-Methylbenzyl)pyridine: a potential liquid organic hydrogen carrier with fast $\mathrm{H} 2$ release and stable activity in consecutive cycles. ChemSusChem 11, 661-665 (2018).

41. Hu, P., Fogler, E., Diskin-Posner, Y., Iron, M. A. \& Milstein, D. A novel liquid organic hydrogen carrier system based on catalytic peptide formation and hydrogenation. Nat. Commun. 6, 6859 (2015).

42. Hu, P., Ben-David, Y. \& Milstein, D. Rechargeable hydrogen storage system based on the dehydrogenative coupling of ethylenediamine with ethanol. Angew. Chem. Int. Ed. 55, 1061-1064 (2016).

43. Kothandaraman, J. et al. Efficient reversible hydrogen carrier system based on amine reforming of methanol. J. Am. Chem. Soc. 139, 2549-2552 (2017).

44. Kumar, A., Janes, T., Espinosa-Jalapa, N. A. \& Milstein, D. Selective hydrogenation of cyclic imides to diols and amines and its application in the development of a liquid organic hydrogen carrier. J. Am. Chem. Soc. 140, 7453-7457 (2018)

45. Xie, Y., Hu, P., Ben-David, Y. \& Milstein, D. A reversible liquid organic hydrogen carrier system based on methanol-ethylenediamine and ethylene urea. Angew. Chem. Int. Ed. 58, 5105-5109 (2019).

46. Elangovan, S. et al. Selective catalytic hydrogenations of nitriles, ketones and aldehydes by well-defined manganese pincer complexes. J. Am. Chem. Soc. 138, 8809-8814 (2016).

47. Mastalir, M., Pittenauer, E., Allmaier, G. \& Kirchner, K. Manganese-catalyzed aminomethylation of aromatic compounds with methanol as a sustainable C1 building block. J. Am. Chem. Soc. 139, 8812-8815 (2017).

48. Kallmeier, F., Dudziec, B., Irrgang, T. \& Kempe, R. Manganese-catalyzed sustainable synthesis of pyrroles from alcohols and amino alcohols. Angew. Chem. Int. Ed. 56, 7261-7265 (2017).

49. Mukherjee, A. \& Milstein, D. Homogeneous catalysis by cobalt and manganese pincer complexes. ACS Catal. 8, 11435-11469 (2018).

50. Zubar, V. et al. Hydrogenation of $\mathrm{CO}_{2}$-derived carbonates and polycarbonates to methanol and diols by metal-ligand cooperative manganese catalysis. Angew. Chem. Int. Ed. 57, 13439-13443 (2018).

51. Kallmeier, F. \& Kempe, R. Manganese complexes for (de)hydrogenation catalysis: a comparison to cobalt and iron catalysts. Angew. Chem. Int. Ed. 57, 46-60 (2018). 
52. Kaithal, A., Hölscher, M. \& Leitner, W. Catalytic hydrogenation of cyclic carbonates using manganese complexes. Angew. Chem. Int. Ed. 57, 13449-13453 (2018).

53. Gorgas, N. \& Kirchner, K. Isoelectronic manganese and iron hydrogenation/ dehydrogenation catalysts: similarities and divergences. Acc. Chem. Res. 51, 1558-1569 (2018).

54. Barman, M. K., Waiba, S. \& Maji, B. Manganese-catalyzed direct olefination of methyl-substituted heteroarenes with primary alcohols. Angew. Chem. Int. Ed. 57, 9126-9130 (2018).

55. Chakraborty, U., Reyes-Rodriguez, E., Demeshko, S., Meyer, F. \& Jacobi von Wangelin, A. A manganese nanosheet: new cluster topology and catalysis. Angew. Chem. Int. Ed. 57, 4970-4975 (2018).

56. Zhang, L., Tang, Y., Han, Z. \& Ding, K. Lutidine-based chiral pincer manganese catalysts for enantioselective hydrogenation of ketones. Angew. Chem. Int. Ed. 58, 4973-4977 (2019).

57. Daw, P., Kumar, A., Espinosa-Jalapa, N. A., Ben-David, Y. \& Milstein, D. Direct synthesis of amides by acceptorless dehydrogenative coupling of benzyl alcohols and ammonia catalyzed by a manganese pincer complex: unexpected crucial role of base. J. Am. Chem. Soc. 141, 12202-12206 (2019).

58. Freitag, F., Irrgang, T. \& Kempe, R. Mechanistic studies of hydride transfer to imines from a highly active and chemoselective manganate catalyst. J. Am. Chem. Soc. 141, 11677-11685 (2019).

59. Das, U. K., Kumar, A., Ben-David, Y., Iron, M. A. \& Milstein, D. Manganese catalyzed hydrogenation of carbamates and urea derivatives. J. Am. Chem. Soc. 141, 12962-12966 (2019).

60. Buhaibeh, R. et al. Phosphine-NHC manganese hydrogenation catalyst exhibiting a non-classical metal-ligand cooperative $\mathrm{H} 2$ activation mode. Angew. Chem. Int. Ed. 58, 6727-6731 (2019).

61. Fu, S., Shao, Z., Wang, Y. \& Liu, Q. Manganese-catalyzed upgrading of ethanol into 1-butanol. J. Am. Chem. Soc. 139, 11941-11948 (2017).

62. Wang, Y., Shao, Z., Zhang, K. \& Liu, Q. Manganese-catalyzed dualdeoxygenative coupling of primary alcohols with 2-arylethanols. Angew. Chem. Int. Ed. 57, 15143-15147 (2018)

63. Shao, Z. et al. A general and efficient Mn-catalyzed acceptorless dehydrogenative coupling of alcohols with hydroxides into carboxylates. Org. Chem. Front. 5, 1248-1256 (2018).

64. Liu, Y. et al. Manganese-catalyzed selective upgrading of ethanol with methanol into isobutanol. ChemSusChem 12, 3069-3072 (2019).

\section{Acknowledgements}

We are grateful for the financial supports from the National Natural Science Foundation of China (21822106 and 91845107), the Beijing Municipal Commission of Science and
Technology (Z181100005118001), and the Foundation of the Department of Education of Guangdong Province (2018KZDXM070).

\section{Author contributions}

Z.S. and Q.L. designed and performed the experiments. Y.L., C.L., W.A., and S.L. helped to complete the experiments. Q.L. directed the project and wrote the paper. All authors interpreted the results on the paper.

\section{Competing interests}

The authors declare no competing interests.

\section{Additional information}

Supplementary information is available for this paper at https://doi.org/10.1038/s41467020-14380-3.

Correspondence and requests for materials should be addressed to Q.L.

Peer review information Nature Communications thanks the anonymous reviewers for their contribution to the peer review of this work. Peer reviewer reports are available.

Reprints and permission information is available at http://www.nature.com/reprints

Publisher's note Springer Nature remains neutral with regard to jurisdictional claims in published maps and institutional affiliations.

(c) Open Access This article is licensed under a Creative Commons Attribution 4.0 International License, which permits use, sharing, adaptation, distribution and reproduction in any medium or format, as long as you give appropriate credit to the original author(s) and the source, provide a link to the Creative Commons license, and indicate if changes were made. The images or other third party material in this article are included in the article's Creative Commons license, unless indicated otherwise in a credit line to the material. If material is not included in the article's Creative Commons license and your intended use is not permitted by statutory regulation or exceeds the permitted use, you will need to obtain permission directly from the copyright holder. To view a copy of this license, visit http://creativecommons.org/ licenses/by/4.0/.

(C) The Author(s) 2020 